\title{
A RECIPROCIDADE NOS CONTRATOS: UMA ANÁLISE EXPRESSIVISTA
}

\author{
Leandro Martins Zanitelli ${ }^{1}$
}

CONTRACTUAL RECIPROCITY: AN EXPRESSIVIST ANALYSIS

\section{RESUMO}

ESTE ARTIGO SE PROPÕE A DETERMINAR POR QUE A LEGISLAÇÃO CONTRATUAL DEVE EXPRESSAR O VALOR DA RECIPROCIDADE. EMBORA MUITO SE VENHA DEBATENDO SOBRE A JUSTIÇA OU O EQUILÍBRIO NOS CONTRATOS E A PROIBIÇÃO À ESTIPULAC̣̃̃O DE CLÁUSULAS ABUSIVAS, POUCA ATENC̣̃̃O TEM SIDO DISPENSADA ÀS QUESTÕES DE SABER SE E POR QUE É IMPORTANTE QUE O VALOR DA RECIPROCIDADE SEJA INCORPORADO AO CONTEÚDO EXPRESSIVO DA LEGISLAÇÃO CONTRATUAL, ISTO É, QUE A LEI, AO REGRAR A ATIVIDADE CONTRATUAL, TORNE PATENTE SUA ADESÃO AO VALOR DA RECIPROCIDADE COMO JUSTICA NAS TROCAS OU RECUSA À EXPLORAÇÃO DE uMA dAS PARTES PELA OUTRA. SEgundo SE DEFENDE AQUI, A EXPRESSÃO LEGAL DO VALOR DA RECIPROCIDADE - QUE PODE ACONTECER SEJA POR INTERMÉDIO DE UM PRINCÍPIO GERAL DE EQUANIMIDADE CONTRATUAL, SEJA POR REQUERIMENTOS MAIS ESPECÍFICOS, TAIS COMO O DA OBSERVÂNCIA DO PRECO MÉDIO (OU “PRECO DE MERCADO) OU - da não estipulação de certas cláusulas - É IMPORTANTE POR DUAS ORDENS DE RAZÕES. PRIMEIRO, O FATO DE A LEI EXPRESSAR O VALOR DA RECIPROCIDADE É DE SE CONSIDERAR IMPORTANTE PORQUE O CONTEÚDO EXPRESSIVO DA LEI - AQUILO QUE A LEI EXPRESSA - É INTRINSECAMENTE IMPORTANTE. NO CASO DA RECIPROCIDADE, SUSTENTA-SE MAIS ADIANTE QUE A LEI, AO MANIFESTAR O ANSEIO DE QUE HAJA CERTO AJUSTE ENTRE O SACRIFÍCIO REALIZADO E A VANTAGEM OBTIDA PELOS CONTRATANTES, ACABA, INDIRETAMENTE, POR PROCLAMAR IDEAIS MAIS BASILARES DE IGUALDADE E FRATERNIDADE. EM SEGUNDO LUGAR, A EXPRESSÃO EM LEI DO VALOR DA RECIPROCIDADE É IMPORTANTE DEVIDO ÀS SUAS CONSEQUÊNCIAS. ESSAS CONSEQUÊNCIAS NÃO SE LIMITAM ÀS QUE RESULTEM DE LIMITES IMPOSTOS À LIBERDADE CONTRATUAL OU À RECUSA DO ÓRGÃO JUDICIAL A EXECUTAR CONTRATOS INÍQUOS, JÁ QUE O ENDOSSO LEGAL AO VALOR DA RECIPROCIDADE PODE INFLUIR SOBRE AS RAZÕES DE AGIR DOS CONTRATANTES, CONTRIBUINDO PARA QUE, AO INVÉS DE AGIR

\section{ABSTRACT}

THIS PAPER TRIES TO ESTABLISH WHY THE LAW OF CONTRACTS SHOULD EXPRESS THE VALUE OF RECIPROCITY. ALTHOUGH SCHOLARS HAVE INTENSIVELY DISCUSSED EQUALITY IN EXCHANGE AND THE PROHIBITION OF UNFAIR TERMS IN CONTRACTS, FEW ATTENTION HAS BEEN PAID TO THE QUESTIONS OF KNOWING IF AND WHY IT MATTERS THAT THE VALUE OF RECIPROCITY BE INCORPORATED TO THE EXPRESSIVE CONTENT OF CONTRACT LAW, THAT IS, THAT THE LAW, THROUGH THE REGULATION OF CONTRACTUAL ACTIVITY, MAKES CLEAR ITS ADHESION TO THE VALUE OF RECIPROCITY AS EQUALITY IN EXCHANGE OR DENYING OF EXPLOITATION OF ONE OF THE PARTIES BY THE OTHER. THE PAPER ARGUES THAT THE LEGAL EXPRESSION OF THE VALUE OF RECIPROCITY - WHICH MAY TAKE PLACE THROUGH EITHER A GENERAL PRINCIPLE OF CONTRACTUAL EQUALITY OR MORE SPECIFIC REQUIREMENTS, AS SUCH THAT OF COMPLYING WITH THE MEAN PRICE (OR "MARKET PRICE") OR THAT OF NOT ESTABLISHING CERTAIN CLAUSES - IS IMPORTANT FOR TWO KINDS OF REASONS. FIRST, THE EXPRESSION BY THE LAW OF THE VALUE OF RECIPROCITY SHOULD BE DEEMED IMPORTANT BECAUSE THE EXPRESSIVE CONTENT OF THE LAW IS INTRINSICALLY IMPORTANT. IN THE CASE OF RECIPROCITY, IT IS ARGUED THAT THE LAW, AS IT MANIFESTS THE WISH THAT THERE BE SOME CORRESPONDENCE BETWEEN THE SACRIFICE MADE AND THE ADVANTAGE OBTAINED BY EACH PARTY, ENDS UP PROCLAIMING, INDIRECTLY, THE MORE BASIC VALUES OF EQUALITY AND FRATERNITY. SECOND, THE LEGAL EXPRESSION OF THE VALUE OF RECIPROCITY IS IMPORTANT IN FACE OF ITS CONSEQUENCES. THESE CONSEQUENCES ARE NOT CIRCUMSCRIBED TO THE ONES COMING FROM LIMITS IMPOSED TO THE FREEDOM OF THE CONTRACTUAL PARTIES OR TO THE REFUSAL OF THE COURTS TO ENFORCE UNFAIR CONTRACTS, SINCE THE LEGAL ENDORSEMENT OF THE VALUE OF RECIPROCITY MAY INFLUENCE THE REASONS FOR ACTING OF THE CONTRACTUAL PARTIES. AS A RESULT, INSTEAD OF 
APENAS PARA A MAXIMIZAÇ̃̃ DO PRÓPRIO GANHO, ELES INCLUAM A SATISFAÇÃO DO INTERESSE DA CONTRAPARTE ENTRE AS RAZÕES DE SUAS DECISÕES. O ARTIGO FOI ORGANIZADO DA SEgUINTE MANEIRA. APÓS A INTRODUÇĀO, QUE CONTÉM BREVES NOTAS SOBRE O EXPRESSIVISMO JURÍDICO, A PARTE II OFERECE UMA DEFINIC̣ÃO GERAL E ALGUMAS CONCEPÇÕES MAIS PRECISAS ACERCA DA RECIPROCIDADE NOS CONTRATOS. EM RELAÇÃO A CADA UMA DESSAS CONCEPÇÕES, REFEREM-SE ALGUMAS DIFICULDADES OU INCONVENIENTES, LIGADOS, SOBRETUDO, À TENTATIVA DE FAZER VALER A RECIPROCIDADE POR MEIO DE RESTRIÇÕES À EFICÁCIA LEGAL DE CONTRATOS ESPONTANEAMENTE CELEBRADOS. A PARTE III É DEDICADA ÀS DUAS FORMAS DE ANÁLISE DA EXPRESSÃO LEGAL DO VALOR DA RECIPROCIDADE, CORRESPONDENTES ÀS DUAS FORMAS DE EXPRESSIVISMO ANTES REFERIDAS; TRATA, PORTANTO, A UMA, DE DEFINIR POR QUE A EXPRESSÃO EM LEI DO VALOR DA RECIPROCIDADE NOS CONTRATOS É INTRINSECAMENTE IMPORTANTE E, A DUAS, DE AVENTAR QUE CONSEQUÊNCIAS ESSA EXPRESSÃO PODE TER - COM ESPECIAL ATENÇÃO, NO ÚLTIMO CASO, À EVENTUAL INFLUÊNCIA QUE O ACRÉSCIMO SIMBÓLICO DO VALOR DA RECIPROCIDADE À LEGISLAÇĀO CONTRATUAL PODE EXERCER SOBRE AS RAZÕES DE AGIR DOS CONTRATANTES. NA PARTE IV, COMPARAM-SE DUAS MANEIRAS PELAS QUAIS O VALOR DA RECIPROCIDADE PODE SER EXPRESSO NA LEGISLAÇÃO: UMA, ABSTRATA, PELA QUAL A RECIPROCIDADE SEJA PROCLAMADA SEM QUE SE FAÇA ALUSÃO A UMA CONCEPCC̃̃O MAIS PRECISA SOBRE AQUILO EM QUE A RECIPROCIDADE CONSISTE, E OUTRA, CONCRETA, NA QUAL TRANSPAREÇA UMA DETERMINADA CONCEPÇÃO DE RECIPROCIDADE OU UMA PARTICULAR DEMANDA PARA A MANUTENÇÃO DA RECIPROCIDADE EM CERTOS CONTRATOS. A PARTE $V$ CONCLUI O ARTIGO COM ALGUMAS SUGESTÕES PARA A PESQUISA FUTURA.

\section{PALAVRAS-CHAVE}

RECIPROCIDADE; CONTRATOS; EXPRESSIVISMO JURÍdICO; JustiçA CONTRATUAL; CONSEQUENCIALISMO
ACTING ONLY IN ORDER TO MAXIMIZE HER OWN GAIN, EACH PARTY MAY INCLUDE THE PROTECTION OF THE INTERESTS OF THE OTHER ONE AMONG THE REASONS OF HER DECISIONS. THIS PAPER WAS ORGANIZED AS FOLLOWS. AFTER THE INTRODUCTION, WHICH CONTAINS SOME BRIEF REMARKS ON LEGAL EXPRESSIVISM, PART II OFFERS A BROAD DEFINITION AND SOME PARTICULAR CONCEPTIONS OF CONTRACTUAL RECIPROCITY. ABOUT EACH ONE OF THESE CONCEPTIONS, SOME DIFFICULTIES OR INCONVENIENCES, WHICH ARE MOSTLY TIED TO THE ATTEMPT OF IMPOSING RECIPROCITY THROUGH THE RESTRICTIONS OF THE LEGAL EFFICACY OF VOLUNTARILY MADE AGREEMENTS, ARE REFERRED TO. PART III IS DEDICATED TO TWO FORMS OF SURVEYING THE LEGAL EXPRESSION OF THE VALUE OF RECIPROCITY, WHICH CORRESPOND TO THE TWO FORMS OF EXPRESSIVISM BEFORE MENTIONED; IT SEEKS TO ESTABLISH, FIRST, WHY THE LEGAL EXPRESSION OF THE VALUE OF CONTRACTUAL RECIPROCITY IS INTRINSICALLY IMPORTANT AND, SECOND, TO ESTIMATE WHICH CONSEQUENCES THAT EXPRESSION MAY HAVE - WITH PARTICULAR ATTENTION, IN THIS LAST CASE, TO THE EVENTUAL INFLUENCE THAT THE SYMBOLIC ADDITION OF THE VALUE OF RECIPROCITY TO THE LAW OF CONTRACTS MAY EXERCISE OVER THE REASONS FOR ACTING OF THE CONTRACTUAL PARTIES. IN PART IV, TWO WAYS BY WHICH THE VALUE OF RECIPROCITY CAN BE EXPRESSED THROUGH LAW ARE COMPARED: ONE, ABSTRACT, BY WHICH RECIPROCITY IS PROCLAIMED WITHOUT ALLUSION TO A MORE PRECISE CONCEPTION ABOUT WHAT RECIPROCITY IS, AND OTHER, CONCRETE, WHICH REVEALS A CERTAIN CONCEPTION OF RECIPROCITY OR A PARTICULAR REQUIREMENT TO OBSERVE RECIPROCITY IN SOME CONTRACTS. PART V CONCLUDES THE PAPER WITH SOME SUGGESTIONS FOR FUTURE RESEARCH.

\section{KEYWORDS}

RECIPROCITY; CONTRACTS; LEGAL EXPRESSIVISM;

Contractual JuSTICE; CONSEQUENTIALISM

\section{INTRODUÇÃO}

Este artigo se propõe a determinar por que a legislação ${ }^{2}$ contratual deve expressar o valor da reciprocidade. Embora muito se venha debatendo sobre a justiça ou o equilíbrio nos contratos e a proibição à estipulação de cláusulas abusivas, pouca atenção tem sido dispensada às questões de saber se e por que é importante que o valor da reciprocidade seja incorporado ao conteúdo expressivo da legislação contratual, ou seja, que a lei, ao regrar a atividade contratual, torne patente sua adesão ao valor da reciprocidade como justiça nas trocas ou recusa à exploração de uma das partes pela outra.

Segundo se defende aqui, a expressão legal do valor da reciprocidade - que pode acontecer seja por intermédio de um princípio geral de equanimidade contratual, ${ }^{3}$ seja por requerimentos mais específicos, tal como o da observância do preço médio (ou "preço de mercado") ou o da não estipulação de certas cláusulas - é importante por duas ordens de razões. Primeiro, o fato de a lei expressar o valor da reciprocidade é de se considerar importante porque o conteúdo expressivo da lei - aquilo que a lei expressa - é intrinsecamente importante. No caso da reciprocidade, sustenta-se que a lei, ao manifestar o anseio de que haja certo ajuste entre o sacrifício realizado 
e a vantagem obtida pelos contratantes, acaba, indiretamente, por proclamar ideais mais basilares de igualdade e fraternidade.

Em segundo lugar, a expressão em lei do valor da reciprocidade é importante devido às suas consequências. Essas consequências não se limitam às que resultem de limites impostos à liberdade contratual ou à recusa do órgão judicial a executar contratos iníquos, já que o endosso legal ao valor da reciprocidade pode influir sobre as razões de agir dos contratantes, contribuindo para que, ao invés de agir apenas para a maximização do próprio ganho, eles incluam a satisfação do interesse da contraparte entre as razões de suas decisões.

Na doutrina legal norte-americana tem-se debatido sobre a importância do conteúdo expressivo das normas jurídicas. ${ }^{4}$ Esse debate gira, resumidamente, em torno de duas hipóteses. A primeira é que os estados mentais, atitudes ou valores expressos pelas normas legais ${ }^{5}$ respondam por parte substancial dos efeitos dessas normas, em outras palavras, que o impacto da lei sobre a população se deva não apenas à sanção por ela cominada, mas também, e de maneira significativa, ao que a lei expressa. A segunda hipótese é que o conteúdo expressivo da lei seja intrinsecamente importante, isto é, que tenhamos razão para considerar uma lei boa ou má simplesmente pelo que ela expressa (e independentemente, portanto, das consequências dessa lei para a população).

Cada uma dessas hipóteses corresponde a uma forma distinta de interesse pelo conteúdo expressivo da lei ou "expressivismo jurídico". 6 No primeiro caso, leva-se em conta o que a norma expressa a fim de determinar (e avaliar) os seus efeitos. Essa forma de expressivismo condiz perfeitamente com o postulado segundo o qual o que importa para estabelecer se uma lei é boa ou má são as suas consequências. A diferença entre esse expressivismo e outras teorias legais consequencialistas, como, por exemplo, a análise econômica do direito tradicional, ${ }^{7}$ está em que o primeiro atenta para o impacto de todo o conteúdo expressivo de uma norma jurídica, e não só o da sanção que ela comina. ${ }^{8}$

Esse último ponto é importante, merecendo ser ilustrado por um exemplo. Comparem-se duas leis de proteção ambiental, uma prevendo multa para casos de infração e a outra permitindo que potenciais poluidores adquiram antecipadamente o direito de poluir até certo limite. Imagine, ainda, que o custo das duas leis para um empresário X seja o mesmo, que ele despenda sob a primeira lei (com o pagamento de multas) o mesmo que sob a segunda (nesse caso, mediante a aquisição antecipada do direito a poluir). Considerando-se apenas a sanção em si, ou seja, o custo legalmente imputado à polução, poder-se-ia afirmar que as leis são similares. Se, no entanto, levarmos em conta o que cada uma dessas leis expressa, notaremos uma diferença importante, capaz inclusive de alterar o seu impacto sobre o meio ambiente. Isso porque, ao tratar a poluição como um ilícito, a primeira lei expressa reprovação ao ato de poluir. No caso da segunda lei, em contrapartida, tal reprovação 
é, ao menos, não tão patente, já que a poluição é ali tratada como objeto de um direito, e não como causa de punição. O expressivismo se distingue de outras teorias consequencialistas por explorar os efeitos de leis que, como as do exemplo dado, diferenciam-se em razão daquilo que expressam.

A segunda forma de expressivismo é não consequencialista ou deontológica. Para os que defendem essa forma de expressivismo, o conteúdo expressivo da lei é importante em si mesmo, e não, ou não apenas, em virtude de suas consequências. Há, assim, uma razão para que a lei expresse certos valores ou atitudes, independentemente das consequências a que a expressão desses mesmos valores ou atitudes dê lugar.

As duas espécies de expressivismo aqui referidas oferecem, portanto, razões diferentes para atentar ao conteúdo expressivo da lei. Ambas se deparam, também, com dificuldades diferentes. Para o expressivismo consequencialista, o conteúdo expressivo da lei é importante porque, a exemplo da sanção legalmente cominada, pode ter impacto sobre o comportamento das pessoas, colaborando (ou não) para a realização de certos objetivos. Afirma-se, assim, que o conteúdo expressivo da lei pode "educar" a população, ocasionar alteração nas normas sociais ou influir sobre preferências e escolhas. Para quem considere o conteúdo expressivo da lei importante por essa razão, as dificuldades consistem em obter provas empíricas dos resultados alcançados pela legislação, bem como em desenvolver modelos que ajudem a prever esses resultados. O expressivismo deontológico, por sua vez, faz levar em conta o conteúdo expressivo da lei em razão da sua importância intrínseca. A dificuldade, em tal caso, consiste em justificar essa importância. Afinal, como observa Sunstein, por que deveríamos insistir em que uma lei expresse certos valores independentemente das consequências, mesmo na hipótese em que essas consequências se mostrem opostas aos valores defendidos? ${ }^{9}$

Essas dificuldades são consideráveis, e o presente artigo não se propõe a fazer qualquer avanço ao seu respeito. ${ }^{10} \mathrm{O}$ objetivo aqui é antes esboçar uma teoria expressivista do direito contratual, apresentando um dos valores, a reciprocidade, que a legislação contratual pode e, conforme se sugere, deve expressar. A expressão desse valor se baseia nas razões próprias às duas vertentes do expressivismo jurídico, ainda que, reitere-se, não se pretenda oferecer a seguir uma defesa dessas razões. Ela se considera, pois, justificável tanto pelas consequências que pode ter para a sociedade em geral e para a atividade contratual em particular (nos moldes, portanto, de um expressivismo consequencialista), quanto pelo valor moral intrínseco daquilo que a legislação expressa (reconhecido pelo expressivismo em sua versão deontológica).

A valorização da reciprocidade nos contratos não é estranha à doutrina legal. No Brasil, essa valorização se manifesta seja pela defesa de um princípio de equilíbrio contratual para o qual falta, ainda, um embasamento legal, geral e explícito, ${ }^{11}$ seja pela aplicação de regras por meio das quais se procura preservar certa proporção 
entre as obrigações das partes sob determinadas circunstâncias, tais como nos casos de lesão (Código Civil, art. 157) e onerosidade excessiva provocada por fato superveniente (Código Civil, art. 478), ou em determinados contratos, como os de adesão (Código Civil, art. 424) e consumo (Lei n. 8.078/1990). ${ }^{12}$

$\mathrm{Na}$ doutrina relativa ao equilíbrio contratual, duas características são, em geral, perceptíveis. Primeiro, é comum associar-se a falta de reciprocidade, ou melhor, o desequilíbrio entre as prestações incumbidas aos contratantes, com a inexequibilidade do contrato. Em outras palavras, costuma-se pressupor que a resposta legal à falta de reciprocidade é a recusa, senão de validade, ao menos de eficácia legal à totalidade ou parte do contrato. Assim sendo, restam duas únicas alternativas: ou se admite a reciprocidade como mandamento do direito contratual, para então negar exequibilidade aos contratos que, por seu conteúdo, demandem demasiado de uma das partes ${ }^{13} \mathrm{ou}$, a fim de negar que a força vinculante de um contrato dependa da equanimidade do seu conteúdo, tem-se de evitar reconhecer a reciprocidade, ao menos no que se refere aos contratos como valor. ${ }^{14}$

Segundo, na mesma medida em que associa a reciprocidade a restrições à liberdade contratual (no sentido de restrições à liberdade das partes para celebrar contratos legalmente eficazes e, portanto, exequíveis), a doutrina costuma reduzir as consequências da expressão em lei do valor da reciprocidade às consequências dessas restrições. Tais consequências são, então, ora aprovadas por autores simpáticos à intervenção estatal, ${ }^{15}$ ora repudiadas pelos defensores do livre mercado. ${ }^{16}$

Uma análise sobre o valor da reciprocidade nos contratos não tem, contudo, que se ater aos limites impostos à liberdade dos contratantes para a preservação do equilíbrio nas trocas, nem, tampouco, deve se reduzir às consequências desses limites. A expressão do valor da reciprocidade na legislação contratual também pode ser avaliada pelo que tem de intrinsecamente bom (ou mau), independentemente, portanto, de suas consequências. O conteúdo expressivo da lei pode, além disso, ter um impacto não relacionado à decisão de negar exequibilidade a determinados contratos ou cláusulas contratuais.

O restante do artigo está organizado da seguinte maneira. A parte II oferece uma definição geral e algumas concepções mais precisas acerca da reciprocidade nos contratos. Em relação a cada uma dessas concepções, referem-se algumas dificuldades ou inconvenientes, ligados, sobretudo, à tentativa de fazer valer a reciprocidade por meio de restrições à eficácia legal de contratos espontaneamente celebrados. A parte III é dedicada às duas formas de análise da expressão legal do valor da reciprocidade, correspondentes às duas formas de expressivismo antes referidas; trata, portanto, a uma, de definir por que a expressão em lei do valor da reciprocidade nos contratos é intrinsecamente importante e, a duas, de aventar que consequências essa expressão pode ter - com especial atenção, no último caso, à eventual influência que o acréscimo simbólico do valor da reciprocidade à legislação contratual pode exercer sobre 
as razões de agir dos contratantes. $\mathrm{Na}$ parte IV, comparam-se duas maneiras pelas quais o valor da reciprocidade pode ser expresso na legislação: uma, abstrata, pela qual a reciprocidade seja proclamada sem que se faça alusão a uma concepção mais precisa sobre aquilo em que a reciprocidade consiste, e outra, concreta, na qual transpareça uma determinada concepção de reciprocidade ou uma particular demanda para a manutenção da reciprocidade em certos contratos. A parte $\mathrm{V}$ conclui o artigo com algumas sugestões para a pesquisa futura.

\section{A RECIPROCIDADE NOS CONTRATOS: IDEIA GERAL E ALGUMAS CONCEPÇÕES}

Entende-se aqui como reciprocidade a qualidade de uma relação contratual que exige sacrifício e propicia vantagem a todos os envolvidos, e na qual se verifica uma certa correspondência entre o sacrifício exigido e a vantagem propiciada a cada uma das partes. A reciprocidade se traduz, portanto, não só por uma mutualidade de custos e benefícios, mas também pela proporcionalidade (igualdade ou semelhança de proporção) entre o custo e o benefício que cada um dos contratantes obtém.

Tratada como valor, a reciprocidade deixa de ser apenas algo observável em algumas relações contratuais para se tornar uma qualidade que essas relações devem, ao menos em boa parte dos casos, ${ }^{17}$ apresentar. Assim, é não apenas um fato o de que, ao invés de servir para a exploração de uma das partes pela outra, os contratos constituem relações de cooperação que remuneram de maneira justa o sacrifício que cada um dos contratantes realiza; essa justa remuneração ou ausência de exploração é também uma condição para a legitimidade do contrato.

Há várias maneiras de traduzir a exigência imposta às relações contratuais pelo valor da reciprocidade, cada uma delas correspondendo a uma resposta diferente à questão de saber qual é a justa medida de remuneração ao sacrifício suportado pelas partes ou o que previne o contrato de ser uma relação exploratória. Considerem-se algumas dessas respostas, de acordo com as quais falta reciprocidade se: (1) o preço a ser pago por um dos contratantes é maior ou menor, ou substancialmente maior ou menor, do que o preço médio; ${ }^{18}$ (2) o contrato, em razão do pouco ou nenhum poder de barganha de uma das partes, estabelece condições que desatendem às preferências da parte em desvantagem; (3) o excedente contratual é desigualmente repartido, sendo inteira ou quase inteiramente apropriado por um dos contratantes. ${ }^{19}$

Contratos exploratórios do tipo "1" podem se verificar se uma das partes, por ignorância ${ }^{20}$ ou necessidade, ${ }^{21}$ submete-se a preço vil ou exorbitante. Em tais casos, porém, pode-se alegar que o mal não reside na falta de reciprocidade em si (verificada pela discrepância entre o preço estipulado e o preço de mercado), mas nas condições sob as quais o consentimento de um dos contratantes foi obtido. Além disso, um inconveniente de se aplicar o requerimento de reciprocidade como observância do preço 
médio reside em que, se o mercado ainda não chegou a um equilíbrio, a intervenção estatal pode dar lugar a um equilíbrio "artificial”, ${ }^{22}$ caracterizado pela escassez de oferta (se o preço considerado justo é inferior ao que resultaria da livre ação das forças de mercado) ou demanda (na hipótese contrária).

Em “2”, a exploração está relacionada à uniformidade de cláusulas característica das práticas de contratação em massa (os “contratos de adesão"). Para a redução de custos administrativos, o empresário subordina os inúmeros contratos que realiza a um ou alguns "contratos-tipo", restando aos consumidores a escolha entre se submeter a um dos modelos contratuais oferecidos ou desistir da contratação. Esses contratos de adesão podem se considerar exploratórios à medida que, em virtude da padronização que impõem, deixem de atender às preferências de alguns consumidores.

Admitindo-se, porém, que os consumidores estejam bem informados e se comportem de maneira racional, a forma de exploração mencionada no parágrafo anterior deve ficar circunscrita a alguns poucos casos, os quais, além disso, não são nada fáceis de constatar. Isso porque se a preferência por uma cláusula $x$ é comum a um grupo relativamente numeroso de consumidores, ${ }^{23}$ é de esperar que, para atrair esse grupo, tal cláusula seja incluída ao menos em um dos tipos de contrato oferecidos, já que o empresário que assim não o fizer ficará em desvantagem frente a seus competidores. ${ }^{24}$ Em consequência, a impossibilidade de realizar um contrato contendo a cláusula $x$ só é de se prever na hipótese de a quantidade de consumidores que preferem $x$ ser pequena a ponto de fazer com que a vantagem competitiva resultante do oferecimento dessa cláusula não compense o acréscimo de custos administrativos daí decorrente. Mesmo que casos assim possam ocorrer, é no mínimo difícil determinar quando acontecem, e quais são, em tais circunstâncias, os consumidores lesados.

Contratos de adesão podem ainda ser tidos como exploratórios se, contrariamente ao que se supôs no último parágrafo, os consumidores não estão adequadamente informados acerca das cláusulas desses contratos ou, mesmo informados, não se comportam de maneira racional. ${ }^{25}$ Com consumidores desinformados ou que não escolhem racionalmente, o incentivo do empresário a incluir no contrato cláusulas que atendam às preferências dos consumidores desaparece, criando-se as condições para o surgimento de um "mercado de limões", com contratos de adesão que contêm cláusulas contrárias às preferências da maioria ou até da totalidade dos consumidores. ${ }^{26}$

O combate à falta de reciprocidade resultante da falta de informação ou irracionalidade dos consumidores também se depara, no entanto, com inconvenientes. Em primeiro lugar, se a falta de informação ou irracionalidade são erroneamente imputadas, a intervenção corre o risco de sujeitar os consumidores a cláusulas não desejadas, ou seja, a cláusulas cujo custo, causador de uma alta no preço do produto ou serviço oferecido, esses consumidores prefeririam não suportar. Além disso, se 
apenas uma parte dos consumidores se encontra mal informada ou propensa a decidir irracionalmente, a proibição à estipulação de uma certa cláusula, ainda que vantajosa a esses consumidores, ${ }^{27}$ pode causar dano aos demais.

Por fim, a falta de reciprocidade correspondente a "3", caracterizada pela desigual repartição do excedente contratual, depende do "preço de reserva", portanto do preço máximo que a parte se dispõe a pagar (ou do mínimo que estaria disposta a aceitar) pelo bem ao qual o contrato diz respeito. ${ }^{28}$ Por exemplo, suponha que $\mathrm{A}$, interessado em comprar automóvel pertencente a $B$, esteja disposto a pagar até $\mathrm{R} \$$ 15 mil pelo carro. Para B, o preço de reserva é R\$ 12 mil, isto é, R \$ 12 mil é a quantia mínima pela qual $\mathrm{B}$ aceitaria se desfazer do mesmo bem. O excedente contratual é a diferença entre os preços de reserva das duas partes, chegando, no caso, a R \$ 3 mil. Logo, para que o contrato não seja exploratório, esse excedente teria de ser igual ou quase igualmente distribuído entre A e $\mathrm{B}$, com o preço do carro ficando em $\mathrm{R} \$ 13.500$ ou próximo a isso.

Esse modo de entender a reciprocidade possui dois inconvenientes, o primeiro deles consistindo em fazer com que a verificação de que um contrato é leonino dependa de indícios a respeito do preço de reserva de cada um dos contratantes, já que é só a partir de informações sobre esse preço que se pode avaliar a equanimidade do preço pactuado. Essas informações, no entanto, podem ser difíceis de obter.

O outro inconveniente é que a ideia de exploração que resulta da exigência de reciprocidade como igual repartição do excedente contratual pode perder sua plausibilidade quando se considerem as razões determinantes do preço de reserva da cada uma das partes. Imagine que B tenha vendido o carro para A por R $\$ 13.500$, mas que, enquanto o preço de reserva de A permaneça em R $\$ 15$ mil, no caso de B esse preço seja agora de R \$ 8 mil. Em tal hipótese, o excedente contratual equivaleria a R $\$ 7$ mil, dos quais uma porção considerável (R \$ 5.500, pouco mais de $80 \%$ ) seria apropriada por B. Ao invés, porém, de abstrair as razões que fizeram com que os preços de reserva dos contratantes fossem esses, suponha que B estivesse disposto a vender o carro por um preço baixo porque precisava desesperadamente de dinheiro para custear o tratamento de um filho doente. Sob tais circunstâncias, não parece plausível afirmar que A tenha sido explorado por B, não mais do que seria se, diferentemente, B não precisasse com urgência do dinheiro e seu preço de reserva ainda fosse $\mathrm{R} \$ 12$ mil (fazendo o preço de $\mathrm{R} \$ 13.500$ corresponder a uma igual divisão do excedente).

\section{A EXPRESSÃO LEGAL DA RECIPROCIDADE: VALOR INTRÍNSECO E CONSEQUÊNCIAS}

Dadas as dificuldades com que se deparam as diferentes concepções de reciprocidade examinadas, que razões haveria para incluir a reciprocidade entre os valores a 
serem expressos pelas normas legais aplicáveis aos contratos? Tal como antes observado, o conteúdo expressivo da legislação pode ser apreciado pela sua importância intrínseca ou devido às consequências a que dá lugar. No que se refere à primeira dessas duas dimensões, não parece difícil sustentar a superioridade de um sistema legal cujas normas contratuais manifestem reconhecimento ao valor da reciprocidade em relação a um outro no qual isso não aconteça. Reconhecer o valor da reciprocidade significa, em primeiro lugar, reconhecer a validade, para o direito contratual, de uma ideia fundamental de igualdade. Como a exigência de reciprocidade é a de que os interesses de uma das partes não sejam subjugados para a realização dos da outra, o que se afirma com a reciprocidade é nada menos do que o igual status dos diferentes contratantes. Em segundo lugar, mais do que a expressão de respeito aos interesses de todos que caracteriza uma sociedade igualitária, o valor da reciprocidade é também o valor de uma sociedade fraterna, na qual as relações entre os cidadãos (entre elas, as relações contratuais) se estabelecem para a mútua cooperação ${ }^{29}$ e não para a obtenção de vantagem a qualquer preço.

O sentido igualitário e fraterno que a legislação contratual adquire mediante o reconhecimento do valor da reciprocidade não depende da maneira como a exigência que esse valor impõe mais concretamente se traduza. Considerando-se apenas o conteúdo expressivo da lei em si mesmo, um sistema jurídico que manifesta a igual consideração e o valor da cooperação dos quais a reciprocidade é, ela mesma, superior a um outro no qual a exploração seja, ainda que não explicitamente, tolerada, independentemente da ideia mais concreta que se faça a respeito do que a reciprocidade exige - estipulação do preço médio; cláusulas que atendam às preferências de ambos os contratantes; igual repartição do excedente contratual; etc. A variedade de posições acerca daquilo a que devem atender as relações contratuais a fim de não se mostrarem exploratórias não impede, em outras palavras, que se atribua superioridade moral a um sistema jurídico em que o valor da reciprocidade seja reconhecido. ${ }^{30}$

No que toca às consequências do conteúdo expressivo da lei, podem-se distinguir as consequências não relacionadas a uma alteração de padrões comportamentais, ou seja, a uma alteração das razões, desejos ou inclinações que influenciam o agir dos contratantes, e as consequências que sejam de atribuir justamente à alteração desses padrões. No primeiro caso, pode-se dizer que as consequências decorrem exclusivamente de fatores externos - como, por exemplo, o agravamento da sanção cominada a uma certa conduta -, enquanto, no segundo, essas consequências estão ligadas a fatores internos ao agente, tais como o aflorar de um novo desejo ou a diversificação do rol de razões para agir.

A diferença entre as duas espécies de consequências pode ser ilustrada com o caso de um fabricante cujas ações sejam de início determinadas exclusivamente pelo objetivo de maximizar lucro. Suponha que esse fabricante tivesse de se sujeitar a uma 
regra de responsabilidade civil pelos danos que os seus produtos causem aos consumidores. Se, uma vez instituída essa regra, as ações do fabricante continuassem pautadas pelo mesmo objetivo, a maximização do lucro, o efeito da norma legal seria levá-lo a tomar providências para tornar seus produtos mais seguros e prevenir danos aos consumidores apenas à medida que o custo marginal (adicional) dessas providências fosse inferior ao custo marginal esperado das indenizações. A proteção à vida e à saúde dos consumidores estaria limitada, em outras palavras, ao ponto a partir do qual a prevenção se tornasse mais cara para o empresário do que a reparação do dano causado. Em tal hipótese, as consequências da lei estariam relacionadas unicamente a um fator externo (a sanção legalmente prevista), já que a razão determinante do agir do fabricante - a maximização do lucro - seria a mesma antes e depois da criação da norma. ${ }^{31}$ Mas imagine agora que, diversamente, a regra sobre responsabilidade civil tenha chamado a atenção para a importância de preservar a vida e a saúde dos consumidores, de tal maneira que, devido à instituição dessa regra e à mensagem que ela veicula, o fabricante deixe de se preocupar apenas com a maximização do lucro e passe a tratar a preservação da vida e da saúde dos consumidores como uma razão para agir independente, e por vezes derrogatória, da anterior. Nessa segunda hipótese, a consequência da lei seria, pois, fazer com que o fabricante tomasse providências para aumentar a segurança dos seus produtos até mesmo em casos nos quais o custo marginal dessas providências superasse o custo marginal esperado das indenizações que, devido à falta de precaução, ele seria obrigado a pagar. Esse aumento da precaução ocorrido em virtude da modificação nas razões aceitas pelo agente seria a consequência de um fator interno - a inclusão da proteção à vida e à saúde dos consumidores entre as razões para a ação - correspondendo, assim, à segunda das espécies de consequências mencionadas acima. ${ }^{32}$

$\mathrm{Na}$ análise das consequências da expressão legal do valor da reciprocidade para os contratos, é preciso levar em conta não apenas as consequências "externas", relacionadas a fatores externos ao agente, mas também as consequências "internas". A expressão do valor da reciprocidade pode influenciar a atividade contratual pelos incentivos que cria - por exemplo, o incentivo a não contratar, em razão dos limites impostos à liberdade contratual - e também pela alteração das motivações dos agentes. Em relação a esse segundo ponto, é de se cogitar, em particular, o quanto o endosso legal ao valor da reciprocidade pode contribuir para incluir a consideração ao interesse da contraparte entre as razões de agir dos contratantes. ${ }^{33}$

À medida que a expressão legal do valor da reciprocidade contribua para imbuir as motivações dos agentes de certo altruísmo, ${ }^{34}$ faz-se dispensável a imposição de limites à liberdade contratual, evitando-se, assim, alguns dos inconvenientes a que pode dar lugar a promoção da reciprocidade quando realizada por meios externos. Observou-se acima que, entendida como observância do preço médio, a reciprocidade pode, se feita valer por meio de intervenção legal ou judicial, resultar em um 
equilíbrio diferente daquele ao qual se chegaria "naturalmente" (isto é, pela livre ação das forças de mercado), no qual oferta ou demanda se mostrem insuficientes. Se a ação dos contratantes deixar de ser pautada exclusivamente pela busca do próprio ganho, no entanto, discrepâncias significativas entre o preço médio e o preço estipulado em cada contrato se tornarão mais raras, reduzindo a necessidade da intervenção estatal.

De maneira similar, o altruísmo que o reconhecimento do valor da reciprocidade pode suscitar diminui a necessidade de intervenção em contratos de adesão. Com empresários comportando-se egoisticamente, as cláusulas de contratos de adesão só atenderão às preferências dos consumidores à medida que os últimos estejam informados acerca do conteúdo dessas cláusulas e aptos a decidir de acordo com suas preferências. Além disso, se as preferências dos consumidores forem heterogêneas, comerciantes dispostos a maximizar seus lucros apenas diversificarão os contratos oferecidos se o ganho proporcionado por essa diversificação superar os custos administrativos daí advindos. A consideração aos interesses da contraparte, no entanto, pode fazer com que os fornecedores de produtos e serviços ajustem as cláusulas contratuais às preferências dos consumidores independentemente do quanto estes estejam informados ou aptos a escolher. ${ }^{35}$ Pela mesma razão, um aumento de custos para a diversificação de contratos pode ser suportado ainda que a vantagem competitiva obtida com essa diversificação não se mostre superior aos custos que ela acarreta. ${ }^{36}$

Finalmente, se a hipótese dos últimos parágrafos estiver correta e a proclamação legal do valor da reciprocidade colaborar para que os contratantes ajam também segundo razões altruístas, outro possível efeito do conteúdo expressivo da lei é uma repartição mais equânime do excedente de certos contratos. Uma vez que os interesses do outro sejam tidos em conta e que o ato de contratar não seja, portanto, guiado pelo exclusivo propósito de obter a máxima vantagem, os contratantes poderão abrir mão de barganhar além de um determinando preço, evitando, assim, aproximar-se do preço de reserva de um ou de outro. Esse efeito, no entanto, depende de que cada uma das partes esteja ao menos medianamente bem informada sobre o preço de reserva da outra (caso contrário, a renúncia à barganha pode piorar, ao invés de tornar mais equânime, a repartição do excedente contratual). Além disso, quando a informação sobre o preço de reserva da contraparte é imperfeita ou os contratantes discordam sobre o que seria uma justa repartição do excedente, o apreço à reciprocidade pode dar lugar a situações de impasse, nas quais as partes se recusem a realizar trocas mutuamente benéficas por considerá-las iníquas.

Para resumir, pode-se dizer que se, por um lado, a realização coerciva do valor da reciprocidade nos contratos de fato padece de certos inconvenientes - risco de redução de bem-estar provocada por um equilíbrio de preços artificial ou pela imposição de cláusulas contratuais contrárias às preferências dos (de todos ou alguns) 
consumidores -, por outro, a expressão legal do valor da reciprocidade não deve ser julgada apenas por esses inconvenientes, mas também pelo seu próprio valor intrínseco e pelas consequências internas a que venha a dar lugar. Essas consequências - e, em particular, o fato de a proclamação legal do valor da reciprocidade contribuir para que se introduza a consideração ao interesse da contraparte entre as razões de agir dos contratantes - podem até mesmo reduzir a necessidade de que a reciprocidade se faça valer por meios externos.

\section{A EXPRESSÃO LEGAL DA RECIPROCIDADE: FORMAS ABSTRATAS E CONCRETAS}

A análise precedente enseja algumas considerações quanto às diversas maneiras mediante as quais o valor da reciprocidade pode ser expresso pela legislação. Uma distinção fundamental a esse respeito é a que põe, de um lado, os casos em que o valor da reciprocidade é expresso de maneira abstrata, não se vinculando, portanto, a uma concepção mais precisa sobre o que seja a reciprocidade, e, do outro, os casos nos quais a alusão à reciprocidade se faz mais concretamente, por meio da adesão legal a uma determinada concepção de justiça contratual ou por particulares exigências para a observância da reciprocidade nos contratos (em todos ou alguns deles). Um exemplo da primeira espécie é dado pelo art. 51, IV, do Código de Defesa do Consumidor (Lei n. 8.078/1990), de acordo com o qual são nulas as cláusulas contratuais que "estabeleçam obrigações consideradas iníquas, abusivas, que coloquem o consumidor em desvantagem exagerada, ou sejam incompatíveis com a boa-fé ou a equidade". Como se pode perceber pela passagem transcrita, o que esse dispositivo expressa é simplesmente a exigência de que os contratos de consumo se abstenham de explorar os consumidores, sem que uma ideia mais precisa acerca daquilo em que tal exploração, a qual se faz alusão por meio das palavras "iníquas", "abusivas", "desvantagem exagerada" e "incompatíveis com a boa-fé ou a equidade", consista. ${ }^{37}$ No Código Civil, um similar requerimento genérico de reciprocidade entende-se expresso pelo art. 421, no qual se proclama o princípio da função social do contrato. ${ }^{38}$ Exemplos da segunda maneira de expressar o valor da reciprocidade são os da Súmula n. 296 do STJ, na qual se estabelece que, em contratos de mútuo bancário, a taxa dos juros remuneratórios depois de findo o prazo contratual deve ser a taxa média de mercado, deixando, assim, ventilar a ideia de que a reciprocidade é realizada nos contratos pela estipulação do preço médio, ${ }^{39}$ e o do art. $52, \S 1^{\circ}$, do já citado Código de Defesa do Consumidor, que limita a multa aplicável ao consumidor em mora a dois por cento do principal devido. ${ }^{40}$

Uma característica das formas de expressão abstrata do valor da reciprocidade é que elas podem inspirar a criação de normas de reciprocidade ex post facto, ou seja, de normas que, para a promoção da equanimidade contratual, reconheçam limites à 
liberdade dos contratantes depois de os contratos já terem sido concluídos. É verdade que isso também pode acontecer com as formas de expressão concreta do mesmo valor, quando a demanda na qual mais concretamente se traduza a exigência de reciprocidade seja aplicada retroativamente, mas, no caso das formas abstratas, o potencial para inspirar limites ex post se mantém mesmo depois que a lei (ou decisão judicial) é promulgada. Exemplificando, enquanto o art. 51, IV, do Código de Defesa do Consumidor pode levar constantemente à nulidade de novas cláusulas contratuais, dando origem a limites à liberdade dos contratantes que serão eventualmente declarados apenas após a realização do contrato, o art. 52, § $1^{\circ}$, do mesmo Código, ainda que aplicado retroativamente, institui tão somente o limite de dois por cento às multas pagas pelos consumidores. ${ }^{41}$

A criação de normas ex post aumenta a probabilidade de que a execução forçada de um contrato se sujeite a limites que não eram nem podiam ser conhecidos pelas partes à época em que o contrato foi realizado, sendo, por isso, importante para a comparação das formas de expressão abstratas e concretas do valor da reciprocidade. Tal comparação não pode, entretanto, restringir-se a isso, nem, em particular, pode se reduzir às repercussões externas (no sentido antes indicado) da insegurança jurídica que as formas abstratas, mais do que as formas concretas, suscitam. Ao invés disso, é preciso examinar também a relação dessas diferentes formas de expressão com o valor inerente do conteúdo expressivo da lei, bem como suas consequências sobre as motivações dos agentes (internas).

Se a expressão do valor da reciprocidade é em si mesma louvável por seu sentido igualitário e fraterno, é imperioso que tal valor seja associado aos contratos em geral, isto é, que a recusa à subordinação dos interesses de um dos contratantes em prol dos do outro e a consideração aos interesses da contraparte sejam, exceção feita aos contratos benéficos, características de toda e qualquer atividade contratual, e não de apenas alguns contratos. Afora isso, o sentido em virtude do qual a reciprocidade há de ser valorizada pode ser encontrado tanto nas formas abstratas quanto nas formas mais concretas de sua expressão. Em outras palavras, as ideias de respeito e generosidade que a reciprocidade contratual traduz tanto podem ser transmitidas por meio de enunciados legais vagos, pelos quais se proclame a reciprocidade sem estabelecer com exatidão em que ela consiste - caso, por exemplo, do art. 421 do Código Civil brasileiro, uma vez entendido o atendimento à função social do contrato como atendimento a um preceito de equilíbrio ou justiça contratual - como por outros nos quais se deixe que uma concepção de reciprocidade em particular, por exemplo, a reciprocidade como observância do preço médio - transpareça.

Não se quer sugerir com o recém-afirmado que a expressão em lei de uma ideia mais precisa de reciprocidade seja irrelevante ou mesmo, no caso de a concepção de reciprocidade escolhida ser genuína, indesejável. Ao contrário, o que se pondera é apenas que a formulação abstrata do conceito de reciprocidade basta para fazer notar 
a adesão de um sistema jurídico a princípios de igualdade e fraternidade, adesão essa que, segundo a posição expressivista aqui aceita, é, por si só, moralmente relevante e louvável. Segue daí que a falta de precisão quanto ao sentido da reciprocidade contratual, decorrente seja da indecisão frente a diferentes concepções, seja do puro e simples não desenvolvimento do conceito, não é, em si mesma, razão para que o valor da reciprocidade deixe de ser expresso, apesar das consequências da imprecisão e, em particular, da insegurança jurídica que ela faz surgir.

Com a ressalva óbvia de que toda hipótese levantada a esse respeito necessita de confirmação empírica, é lícito aventar que a influência do conteúdo expressivo da lei sobre as razões dos agentes, e, em especial, a infusão de uma certa dose de altruísmo em tais razões, ocorra de maneira igualmente intensa, ou até mais intensa, nos casos em que o valor da reciprocidade é expresso abstratamente. A simples alusão à ideia de que as trocas devem ser justas ou de que o contrato não deve servir de meio de exploração de uma das partes pela outra pode bastar para que o valor da reciprocidade seja internalizado, portanto para que os próprios contratantes deixem de ver a relação em que se encontram como instrumento para a maximização do próprio ganho e incluam a realização do interesse do outro entre suas razões para agir. Além disso, comparada a casos nos quais a lei se limite a exigir a observância do preço médio ou a proibir a estipulação de certas cláusulas por considerá-las abusivas, a exigência de reciprocidade feita em abstrato parece evocar com mais clareza os valores da igualdade e da fraternidade, podendo, em consequência, mostrar-se mais eficaz no que diz respeito à alteração das motivações das partes.

\section{${ }_{4}$ CONCLUSÕES}

Este texto convida a fazer avançar duas linhas de investigação sobre a reciprocidade nos contratos. Ambas vão além, embora, é claro, não sejam indiferentes à questão de determinar em que a reciprocidade consiste. A primeira dessas linhas se refere à expressão da reciprocidade em si mesma: um sistema jurídico no qual se proclame a reciprocidade como valor contratual é, desconsiderando-se todo o resto, moralmente superior a um outro que não o faça? Há, em outras palavras, alguma razão para que a expressão do valor da reciprocidade na legislação contratual seja louvada por si mesma, independentemente das suas consequências? A resposta acima oferecida para essas perguntas foi afirmativa, mas é plausível supor que algo mais ainda se possa dizer a esse respeito.

A segunda linha de investigação é a que se refere às consequências da expressão em lei do valor da reciprocidade contratual. Essa linha tem sido bastante explorada, especialmente por autores ligados à análise econômica do direito, no que toca às consequências da intervenção estatal ocorrida mediante a recusa a executar contratos iníquos. $^{42}$ Falta, entretanto, que esse trabalho - seja com o desenvolvimento de 
modelos preditivos, seja com a busca de evidências empíricas - estenda-se a consequências outras que não as da intervenção estatal em mercados habitados por agentes autointeressados. Em particular, seria importante estimar ou verificar o efeito da expressão legal do valor da reciprocidade sobre normas sociais, bem como o seu impacto sobre as razões de agir dos contratantes - o que aqui se denominou de efeito interno do conteúdo expressivo da legislação.

: ARTIGO APROVADO (10/09/2010) : RECEBIDO EM 19/03/2010

\section{NOTAS}

$1 \mathrm{O}$ autor agradece ao UniRitter/RS e à Fundação de Amparo à Pesquisa do Estado do Rio Grande do Sul (FAPERGS) pelo apoio à realização da pesquisa.

2 Por "legislação" entenda-se aí a totalidade do sistema jurídico, e não, portanto, apenas a parte desse sistema que é composta de leis em sentido mais estrito.

3 Como é na doutrina brasileira o "princípio do equilíbrio" ou, no entender de alguns, o princípio da função social do contrato estabelecido pelo art. 421 do Código Civil. V, a respeito, as referências contidas nas notas 10 e 37, infra.

4 Entre os autores simpáticos ao que se vem chamando de "expressivismo jurídico" (legal expressivism) estão, p.ex., Cass Sunstein (1996, p. 2021); Richard H. Pildes (1998, p. 725); Elizabeth S. Anderson; Richard H. Pildes (2000, p. 1503); Deborah Hellman (2000, p. 1). Para opiniões discordantes, v. Matthew D. Adler (2000, p. 1363); Steven S. Smith (2001, p. 506); Heidi M. Hurd (2005, p. 405).

5 Esses estados mentais, atitudes ou valores são aqueles que uma norma pareça manifestar, ainda que não sejam os mesmos que os autores da lei possuíssem ou intentassem comunicar ao promulgá-la. Uma lei, portanto, pode ser tratada como expressão de ódio racial mesmo que não haja entre os seus autores qualquer animosidade contra o grupo ao qual a lei causa dano. V. Anderson \& Pildes (2000, p. 1523-1524).

6 V. Lewis A. Kornhauser (1998, p. 1599, 1624-1625) - distinguindo a opinião segundo a qual o conteúdo expressivo da lei tem um valor meramente instrumental, ou seja, é importante apenas à medida que educa a população e assim colabora para a realização de certos objetivos, e a opinião segundo a qual o conteúdo expressivo da lei possui valor intrínseco.

7 Por "análise econômica tradicional" entenda-se aí uma que se limite aos incentivos decorrentes das sanções legais, ignorando, portanto, as possíveis consequências comportamentais do conteúdo expressivo da lei como um todo.

8 Uma outra distinção entre teorias legais consequencialistas é a que separa, de um lado, aquelas que tratam preferências (no sentido de gostos ou convicções) como exógenas e, de outro, as que cogitam de alteração nas preferências de uma população em virtude das normas legais. Para uma teoria da primeira espécie, a lei influi sobre as escolhas da população apenas à medida que altera o "preço" de certas condutas. O fumante inveterado, por exemplo, não passa a gostar menos do cigarro por causa de uma lei que proíbe o fumo em lugares públicos, mas pode ter o seu comportamento alterado em razão do custo adicional que essa lei atrela ao consumo do cigarro. Já uma teoria da segunda espécie conta com possíveis modificações nas preferências da população em decorrência das normas legais, como no caso do fumante que é persuadido pela mesma lei acerca da inconveniência do fumo e para o qual então o consumo do cigarro se torna menos desejável. 
Embora seja altamente plausível supor que o conteúdo expressivo da lei tenha impacto sobre as preferências (e não apenas sobre as escolhas) dos cidadãos, o que distingue o expressivismo consequencialista é a atenção às consequências desse conteúdo como um todo, e não pertencer ao rol de teorias da segunda das duas espécies aqui mencionadas.

9 V. Sunstein (1996, p. 2045). Para Sunstein, o único expressivismo defensável é o expressivismo consequencialista.

10 Procurei defender o expressivismo deontológico em um artigo anterior, Avaliando a lei pelo que ela expressa: o fundamento moral do expressivismo jurídico, inédito. Nesse artigo, argumento que o conteúdo expressivo da lei possui uma importância moral objetiva, independente da qualidade moral das condutas que lhe deram origem. Tal importância decorre do próprio caráter expressivo da legislação ou do fato de o sistema jurídico, à medida que é encarado como sistema jurídico de um povo, ser expressão das crenças, valores e atitudes desse povo.

11 A legislação brasileira não institui de maneira expressa um princípio de equilíbrio para os contratos. Referências ao princípio do equilíbrio podem ser encontradas, não obstante, em Fernando Noronha (1994, p. 205-249); Antonio Junqueira de Azevedo (1998, p. 113, 116); Teresa Negreiros (2006, p. 156-206). Além disso, parte da doutrina trata o princípio da função social do contrato instituído pelo art. 421 do Código Civil como um princípio que demanda, entre outras coisas, equilíbrio nas trocas. V., a esse respeito, as referências contidas na nota 37 , infra.

12 A Lei n. 8.078/1990 do Código de Defesa do Consumidor trata de manter o equilíbrio nos contratos de consumo especialmente mediante a proibição a cláusulas abusivas (v., em particular, o art. 51) e a proteção ao consumidor contra a onerosidade excessiva decorrente de fato superveniente (art. $6^{\circ}, \mathrm{V}$, in fine).

13 V., p. ex., Negreiros (2006, p. 160): "um contrato livremente pactuado pode ser, não obstante, um contrato injusto e, nesta medida, pode ser revisto, modificado judicialmente ou mesmo integralmente rescindido" (grifo do autor).

14 Como parece fazer Luciano Benetti Timm (2008, p. 77), v., em especial, o cap. IV, no qual o autor afirma que, ao invés de combater o desequilíbrio verificado em algumas relações, o direito contratual deve se contentar em reduzir custos de transação e contribuir assim para o "bom funcionamento do mercado".

15 Talvez se devesse falar em não intervenção estatal quando a lei nega eficácia a contratos ou cláusulas iníquas, pois o que ocorre nesses casos é a recusa do Estado, por meio de seus órgãos judiciais, a fazer cumprir o que foi pactuado ou a aplicar sanção à parte renitente. O mais comum, entretanto, é usar-se o termo "intervenção" para esses casos e tratar como de não intervenção aqueles nos quais o Estado impõe o cumprimento do contrato.

16 Em defesa das consequências de uma intervenção estatal nos contratos destinada a preservar o equilíbrio contratual, v. James Gordley afirmando que a observância do justo preço, entendido como o preço de mercado, evita uma redistribuição de riquezas não planejada (1981, p. 1587, 1609-1617). Para um ponto de vista contrário, v. Richard A. Epstein, para quem a recusa a executar um contrato é justificável apenas em caso de vício da vontade ou "procedural unconscionability"; quando, ao contrário, a intervenção estatal se baseia apenas no conteúdo do contrato - "substantive unconscionability" -, sua tendência é contrariar o interesse dos contratantes e assim causar mais dano do que benefício (1975, p. 293)

17 Aceitar a reciprocidade como valor não impede que se reconheçam relações contratuais dominadas pelo altruísmo, às quais, portanto, tal valor é estranho.

18 Sobre reciprocidade como observância do preço médio, ou “preço de mercado”, v. James Gordley (1981).

O preço médio que se tem em vista pode ser o da época em que o contrato foi realizado ou, diversamente, o que é verificado algum tempo depois. A ideia de reciprocidade correspondente a esse segundo caso, isto é, reciprocidade como observância do preço médio superveniente, traz consigo uma complicação adicional pelo fato de a diferença entre o preço pactuado e o preço médio observado supervenientemente poder ou não ser atribuída ao ganho excessivo de uma das partes (ganho esse que a ação das forças de mercado teria paulatinamente tratado de impedir, resultando no preço médio atual). Em outras palavras, a diferença entre o preço estipulado e o preço médio apurado posteriormente pode se dever a fatores outros (como a situação de outros mercados) que não o locupletamento de uma das partes.

19 As respostas mencionadas não são, naturalmente, as únicas possíveis. Outra maneira de conceber a reciprocidade consistiria em equipará-la à proporcionalidade entre o sacrifício e o ganho que do contrato resultam para cada um dos envolvidos. Devido ao limite de espaço, no entanto, este artigo se restringirá às três concepções apresentadas no texto. 
20 A ignorância pode se dever à ocasional falta de informação sobre as qualidades do bem adquirido ou, simplesmente, à inexperiência.

21 Caso, por exemplo, dos "contratos de salvamento".

22 Diferente daquele ao qual naturalmente levariam as forças de mercado.

23 Se a cláusula em questão acarreta custos adicionais para o empresário (p.ex., uma cláusula de garantia contra vícios ocultos, quando comparada a uma cláusula de exclusão de garantia), a preferência a que se refere o texto deve ser entendida como a disposição dos consumidores a pagar pela inclusão dessa cláusula no contrato uma quantia no mínimo igual aos custos daí decorrentes.

24 À falta de competição, o incentivo do fornecedor para preestabelecer cláusulas conformes às preferências dos consumidores é menor. Ainda assim, nada assegura que tais cláusulas não farão parte dos contratos, já que o empresário pode tirar proveito da posição de monopolista apenas mediante a estipulação de preços em patamares superiores aos competitivos. V. George L. Priest afirmando que, "geralmente, lucros monopolistas são maximizados mediante a venda de produtos idênticos em tudo [exceto preço] aos oferecidos sob competição" - "generally, monopoly profits are maximized by selling a product identical in all respects [except price] to the product offered under competition" -, (1981, p. 1297, 1321).

$25 \mathrm{O}$ abandono da suposição de racionalidade dos consumidores caracteriza a "economia comportamental" (behavioral economics) ou o "direito e economia comportamental" (behavioral law and economics). V. Christine Jolls, Cass R. Sunstein; Richard Thaler (1998, p. 1.471). Sobre a irracionalidade dos consumidores submetidos a contratos de adesão, v. Russel Korobkin (2003, p. 1203); Oren Bar-Gill (2008, p. 749).

26 Sobre isso, v. George A. Akerlof (1970, p. 488).

27 Da falta de informação ou irracionalidade só é válido inferir que os contratos de adesão podem desatender às preferências dos consumidores. Tendo em vista o custo de cláusulas alternativas, nada impede que as cláusulas impostas a consumidores mal informados ou irracionais sejam as mesmas que consumidores informados e racionais escolheriam.

28 Se o bem é daqueles que se comercializam com frequência, o preço de reserva dos contratantes deve ficar próximo ao preço de mercado ou preço médio. Afinal, por mais que o potencial comprador necessite do bem oferecido ou que o dono desse bem necessite vendê-lo, nenhum dos dois tem razão para se dispor a pagar significativamente mais ou a aceitar significativamente menos do que a quantia pela qual bens similares àquele são rotineiramente negociados. Uma considerável diferença entre os preços de reserva das duas partes está mais propensa a ocorrer, portanto, no caso de bens infungíveis (para os quais não há um preço de mercado) ou quando, apesar de haver mercado, uma das partes não tem acesso a ele (ou seja, não está em condições de negociar com outras pessoas). Nessa última hipótese, a reciprocidade pode ser entendida seja como observância do preço médio, seja como igual repartição do excedente contratual.

29 Além da busca pela realização do próprio interesse, a cooperação a que se refere o texto envolve um sentimento favorável à realização do interesse do outro. Esse sentimento está ausente nas relações exploratórias, as quais, portanto, não chegam a constituir relações de cooperação no sentido a que se alude acima, ainda que, eventualmente, revelem-se vantajosas para ambas as partes.

30 A vantagem de se apregoar o valor da reciprocidade desapareceria (ao menos no que diz respeito ao conteúdo expressivo da lei em si mesmo, isto é, como algo a que se atribui importância intrínseca) apenas se a ideia de reciprocidade se mostrasse destituída de sentido. Como demonstram as diversas concepções examinadas, no entanto, esse não é o caso.

31 Para uma análise das consequências da responsabilidade civil baseada na suposição de que a razão determinante do agir dos potenciais responsáveis seja a maximização da própria riqueza, v. Steven Shavell (1987).

32 Se o aumento da precaução ocorre devido ao abalo à reputação causado pelo acidente e ao efeito desse abalo sobre as vendas, trata-se de uma consequência meramente externa, a qual é de atribuir não à norma legal de responsabilidade propriamente dita, mas a uma norma social sobre a segurança dos produtos. $\mathrm{O}$ abalo à reputação e a subsequente queda nas vendas juntam-se à eventual condenação judicial a reparar o dano para constituir o "preço" a pagar pela falta de prevenção, não podendo deixar de ser levados em conta, portanto, pelo empresário cujo exclusivo interesse seja maximizar lucros. 
33 O texto se refere à consideração ao interesse da contraparte como razão "última", não subordinada a nenhuma outra. O que se tem em vista, assim, é o comportamento genuinamente altruísta, e não os casos em que um dos contratantes trata de atender ao interesse do outro estrategicamente, ou seja, apenas com o fito de obter alguma vantagem no futuro.

34 Embora não se esteja em condições aqui de oferecer qualquer evidência empírica de que isso aconteça, a afirmação segundo a qual a expressão de valores pelo sistema legal é capaz de levar os cidadãos a tratar esses valores como razões para agir soa como truísmo. O que resta a verificar, portanto, é em que medida, ou sob que condições, a adesão de um sistema jurídico ao valor da reciprocidade afeta as motivações dos contratantes.

35 Isso depende, é claro, de que os fornecedores percebam corretamente as preferências dos consumidores.

36 O empresário preocupado em satisfazer aos interesses da contraparte deve, porém, levar em conta a alta de preços provocada pela diversificação de contratos e assim ponderar dois interesses distintos dos consumidores, o de pagar preços menores e o de contar com cláusulas contratuais adequadas às suas preferências.

37 A referida imprecisão apenas se mantém depois que se acrescenta, no $\S 1^{\circ}$ do mesmo art. 51, que a vantagem contratualmente atribuída ao fornecedor se presume exagerada quando "I - ofende os princípios fundamentais do sistema jurídico a que pertence; II - restringe direitos ou obrigações fundamentais inerentes à natureza do contrato, de tal modo a ameaçar seu objeto ou o equilíbrio contratual; III - se mostra excessivamente onerosa para o consumidor, considerandose a natureza e conteúdo do contrato, o interesse das partes e outras circunstâncias peculiares ao caso".

38 Código Civil, art. 421: "A liberdade de contratar será exercida em razão e nos limites da função social do contrato.” Sobre o princípio da função social do contrato como princípio de equanimidade ou justiça contratual, v. Bruno Miragem (2005, p. 22, 25); Luis Renato Ferreira da Silva (2006, p. 147, 158). A doutrina brasileira também tem atribuído ao princípio da função social a extensão dos efeitos legais do contrato a terceiros. V., p. ex., Antonio Junqueira de Azevedo (1998, p. 113, 116-117); Judith Martins-Costa (2005, p. 65, 94-102).

39 Súmula n. 296 do STJ: "Os juros remuneratórios, não cumuláveis com a comissão de permanência, são devidos no período de inadimplência, à taxa média de mercado estipulada pelo Banco Central do Brasil, limitada ao percentual contratado". Devido à ressalva feita na parte final da Súmula, a taxa aplicada só será a taxa média nos casos em que a taxa estipulada contratualmente for igual ou superior a essa última.

40 Código de Defesa do Consumidor (Lei n. 8.078/1990), art. 52, § $1^{\circ}$ : "As multas de mora decorrentes do inadimplemento de obrigação no seu termo não poderão ser superiores a $2 \%$ (dois por cento) do valor da prestação”.

41 É verdade que formas concretas de expressão do valor da reciprocidade também podem inspirar limites outros à liberdade contratual que não aqueles pelos quais a ideia de reciprocidade é expressa, como no caso de o art. $52, \S 1^{\circ}$, do Código de Defesa do Consumidor levar, por analogia, à imposição do limite de dois por cento às multas de mora em contratos que não são de consumo. Na história recente do Direito brasileiro, entretanto, casos assim não são tão frequentes quanto os de surgimento de limites à liberdade contratual decorrente das formas abstratas de expressão da reciprocidade.

42 V. Epstein (1975).

\section{REFERÊNCIAS BIBLIOGRÁFICAS}

ADLER, Matthew D. Expressive theories of law: a skeptical overview. University of Pennsylvania Law Review, v. 148, p. 1363-1501, mai. 2000.

AKERLOF, George A. The market for "lemons": quality uncertainty and the market mechanism. Quarterly Journal of Economics, v. 84, p. 488-500, ago. 1970.

ANDERSON, Elizabeth S.; PILDES, Richard H. Expressive theories of law: a general restatement. University of Pennsylvania Law Review, v. 148, p. 1503-1575, mai. 2000. 
AZEVEDO, Antonio Junqueira de. Princípios do novo direito contratual e desregulamentação do mercado, direito de exclusividade nas relações contratuais de fornecimento, função social do contrato e responsabilidade aquiliana do terceiro que contribui para inadimplemento contratual. Revista dos Tribunais, v. 750, p. 113-120, abr. 1998. BAR-GILL, Oren. The behavioral economics of consumer contracts. Minnesota Law Review, v. 92, n. 3, p. 749-802, fev. 2008.

EPSTEIN, Richard A. Unconscionability: a critical reappraisal. Journal of Law \& Economics, v. 18, p. 293-315, 1975. GORDLEY, James. Equality in exchange. California Law Review, v. 69, p. 1587-1656, dez. 1981.

HELLMAN, Deborah. The expressive dimension of equal protection. Minnesota Law Review, v. 85, p. 1-69, nov. 2000 .

HURD, Heidi M. Expressing doubts about expressivism. The University of Chicago Legal Forum, v. 2005, p. 405 435, 2005.

JOLLS, Christine; SUNSTEIN, Cass R.; THALER, Richard. A behavioral approach to law and economics. Stanford Law Review, v. 50, p. 1471-1550, mai. 1998.

KORNHAUSER, Lewis A. No best answer? University of Pennsylvania Law Review, v. 146, p. 1599-1637, jun. 1998. KOROBKIN, Russel. Bounded rationality, standard form contracts, and unconscionability. University of Chicago Law Review, v. 70, p. 1203-1296, 2003.

MARTINS-COSTA, Judith. Reflexões sobre o princípio da função social do contrato. Revista Brasileira de Direito Comparado, v. 29, p. 65-102, jul.-dez. 2005.

MIRAGEM, Bruno. Diretrizes interpretativas da função social do contrato. Revista de Direito do Consumidor, v. 56, p. 22-45, out./dez. 2005.

NEGREIROS, Teresa. Teoria do contrato: novos paradigmas. 2. ed. Rio de Janeiro: Renovar, 2006. 544 p.

NORONHA, Fernando. O direito dos contratos e seus princípios fundamentais: autonomia privada, boa-fé, justiça contratual. São Paulo: Saraiva, 1994. 263 p.

PILDES, Richard H. Why rights are not trumps: social meanings, expressive harms and constitutionalism. Journal of Legal Studies, v. 27, p. 725-762, jun. 1998.

PRIEST, George L. A theory of the consumer product warranty. Yale Law Journal, v. 90, p. 1297-1352, 1981.

SHAVELL, Steven. Economic Analysis of Accident Law. Cambridge, Massachusetts: Harvard University, 1987. 320 p. SILVA, Luis Renato Ferreira da. A função social do contrato no Novo Código Civil e sua conexão com a solidariedade social. In: SARLET, Ingo Wolfgang. (Org.) O Novo Código Civil e a Constituição. Porto Alegre: Livraria do Advogado, 2006, p. 147-170.

SMITH, Steven S. Expressivist jurisprudence and the depletion of meaning. Maryland Law Review, v. 60, p. $506-$ $577,2001$.

SUNSTEIN, Cass. On the expressive function of law. University of Pennsylvania Law Review, v. 144, p. 2021-2053, mai. 1996.

TIMM, Luciano Benetti. O Novo Direito Civil: ensaios sobre o mercado, a reprivatização do direito civil e a privatização do direito público. Porto Alegre: Livraria do Advogado, 2008. 204 p.

ZANITELLI, Leandro Martins. Avaliando a lei pelo que ela expressa: o fundamento moral do expressivismo jurídico, inédito.

Leandro Martins Zanitelli

Rua Santos Dumont, 888

Niterói - 92120-110

Canoas - RS - Brasil

leandro zanitelliduniritter.edu.br
DOUTOR EM DIREITO PELA UFRGS

Professor Titular da UniRitter/RS 
